\title{
Differentiation of osteoblast-like cells and ectopic bone formation induced by bone marrow stem cells transfected with chitosan nanoparticles containing plasmid-BMP2 sequences
}

\author{
ZHANG QING HONG, LIU MENG TAO and ZHANG XIAO BIN \\ Department of Prosthodontics, Hangzhou Mengtao Dental Clinic, Hangzhou, Zhejiang 310018, P.R. China
}

Received August 11, 2015; Accepted November 1, 2016

DOI: $10.3892 / \mathrm{mmr} .2017 .6128$

\begin{abstract}
The present study investigated the efficiency of the use of chitosan nanoparticles containing plasmid-bone morphogenetic protein 2 (pBMP2) sequences (CNPBs) to induce the differentiation of bone marrow stem cells (BMSCs) into osteoblast-like cells that may be able to promote ectopic bone formation. pBMP2s were constructed, and chitosan nanoparticles were incubated with 50,100 or $200 \mu \mathrm{g} / \mathrm{ml}$ pBMP2. BMSCs were collected from the tibiae and femurs of 6-week old rats, cultured and treated with the CNPBs or $200 \mu \mathrm{g} / \mathrm{ml} \mathrm{pBMP} 2$ as a positive control. Transfection efficiency was confirmed using the green fluorescent protein assay. Histological staining methods, including alkaline phosphatase, Wright's and von Kasso staining, were used to identify features of osteoblast-like cells differentiated from BMSCs. Expression levels of the markers of osteoblasts, such as alkaline phosphatase, osteoprotegerin, osteocalcin and osteopontin, were determined to verify the differentiation of BMSCs into osteoblast-like cells. Ectopic bone formation was observed following the integration of polyglycolic acid (PGA) scaffolds with CNPBs and BMSCs, which were implanted into the dorsal muscles of Sprague-Dawley rats. Exposure to CNPBs led to the transfection of BMSCs with BMP2. The transfected BMSCs possessed the characteristic phenotypes of osteoblasts. The expression levels of alkaline phosphatase, osteoprotegerin, osteocalcin and osteopontin were significantly higher in the transfected cells compared with the control group, particularly
\end{abstract}

Correspondence to: Dr Liu Meng Tao, Department of Prosthodontics, Hangzhou Mengtao Dental Clinic, 1125 Avenue 2, Hangzhou, Zhejiang 310018, P.R. China

E-mail: cellresearch@163.com

Abbreviations: BMP2, bone morphogenetic protein 2; CNPBs, chitosan nanoparticles containing plasmid-bone morphogenetic protein 2 sequences; BMSC, bone marrow stem cells; pBMP2s, plasmid-BMP2s; PGA, polyglycolic acid; GFP, green fluorescent protein

Key words: chitosan, BMP2, osteoblast, bone marrow, bone tissue engineering, bone repair the CBP200 group. PGA scaffolds integrated with BMSCs and CNPBs induced ectopic bone formation, as changes in the morphology of cells were observed using histological staining. Therefore, CNPBs may be a promising method of promoting the formation of novel bone tissue.

\section{Introduction}

Bone tissue engineering provides a method for repair of bone defects $(1,2)$. The rapid development of bone tissue engineering in combination with neogenetic osteoblast-like cells, bone tissues induced by seed cells, genetic carrier delivery systems, bioscaffolds and growth factors may have the potential to replace autogenous bone transplantation in segmental bone repair $(3,4)$. Previous studies have used techniques on the nanometer scale for tissue engineering $(5,6)$.

Bone marrow stem cells (BMSCs) may be induced to differentiate into osteoblast-like cells during osteogenesis. However, there is a limited number of BMSCs in the bone marrow, and BMSCs alone are unable to induce new bone formation (7). Therefore, it is difficult to use only BMSCs to promote the repair of bone defects. In order to induce BMSCs to differentiate into osteoblast-like cells, bone growth factors are required (8).

Bone morphogenetic protein 2 (BMP2) is a bone growth factor that may be used to induce osteogenesis (9). However, it is difficult to sustain the slow release of high concentrations of exogenous bone growth factors in the region of the bone defect. In addition, high doses of exogenous bone growth factors may lead to adverse side-effects in the patient. Therefore, it is crucial to identify a method of releasing BMP2 slowly, and at high concentrations, within the regions of defective bone by using genetic carriers (10).

Non-viral carriers are safer alternatives to viral carriers (11). Chitosan is a biocompatible and bioresorbable polymer of $\mathrm{N}$-acetylglucosamine and glucosamine, and it is extensively used as a carrier for bone growth factors (12). Favorable characteristics of chitosan for this purpose include its easy availability, low cytotoxicity, low immunogenicity, excellent biocompatibility and improved biodegradability. A previous study confirmed that chitosan may deliver exogenous BMP2 into various seed cells, such as BMSCs (13). In addition, chitosan nanoparticles are advantageous for delivering bone growth factors or gene sequences into seed cells in order to 
induce the formation of bone tissues with high efficiency (14) due to their excellent properties of infiltration and absorption. In the course of delivery, DNA combined with chitosan nanoparticles was effectively protected, and consequently, genes and proteins remained functional for longer periods of time.

In our previous study, chitosan nanoparticles containing plasmid-BMP2 (pBMP2) sequences (CNPBs) were constructed through using re-coacervation and gene recombination techniques (15). Our previous study determined that the average diameter of chitosan nanoparticles was $90 \pm 20 \mathrm{~nm}$. CNPBs with higher enveloping ratios were able to effectively protect BMP2 genes. Following incubation of BMSCs with CNPBs for 12 days, cells had maintained their normal morphology and function (15).

In the present study, CNPBs were constructed with different concentrations of pBMP2, specifically containing $50 \mu \mathrm{g} / \mathrm{ml}$ (CPB50), $100 \mu \mathrm{g} / \mathrm{ml}$ (CPB100) or $200 \mu \mathrm{g} / \mathrm{ml}$ (CPB200) pBMP2. Following treatment with CNPB, groups were separately phagocytized by BMSCs. The transfection efficiency of the CNPBs was confirmed, and features of osteoblast-like cells derived from BMSCs were observed through histological staining, including alkaline phosphatase, Wright's and von Kasso staining. Expression levels of osteoblast-associated molecules, such as alkaline phosphatase (ALP), osteoprotegerin (OPG), osteocalcin (OC) and osteopontin (OPN), were detected and analyzed in the differentiated osteoblast-like cells. Ectopic bone formation was observed following the integration of polyglycolic acid (PGA) scaffolds with CNPBs and BMSCs, which were implanted into the dorsal muscles of Sprague-Dawley rats.

\section{Materials and methods}

Ethics statement. All animals used in this study were provided by the experimental animal center of Zhejiang University, (Zhejiang, China). The animal use and care protocol was approved by the Institutional Animal Use and Care Committee of Zhejiang University. Experimenters were approved through the Health Department of Zhejiang Province for experiments with animals (certificate no. x0901616).

Culture of BMSCs and construction of CNPBs. A total of 10 female Sprague Dawley rats were anesthetized with pentobarbital sodium (50 mg/kg, Sigma-Aldrich Merck Millipore, Darmstadt, Germany) and sacrificed by cervical dislocation (6-weeks old; weight, 180-220 g; sanitary degree). The animals were kept in air-circulated housing a $14 \mathrm{~h}$ light $/ 10 \mathrm{~h}$ dark cycle at $22 \pm 2^{\circ} \mathrm{C}$. Bones were dissected from the rats using a surgical knife. Bone marrow cavities of tibias and femoral bones were rinsed using phosphate buffered saline (PBS). Cells were centrifuged at $300 \mathrm{x} g$ for $5 \mathrm{~min}$ at $37^{\circ} \mathrm{C}$ and cultured in Dulbecco's modified Eagle's medium (DMEM; GE Healthcare Life Sciences, Logan, UT, USA) containing 10\% fetal bovine serum (FBS; Gibco; Thermo Fisher Scientific, Inc., Waltham, MA, USA). Next, BMSCs were subjected to digestion with $0.25 \%$ trypsin (Gibco; Thermo Fisher Scientific, Inc.), cells were cultured until passage 3 and used in the subsequent experiments. In our previous study (15), CNPBs were constructed using re-coacervation and gene recombination techniques. Escherichia coli bacteria were transfected with plasmids (cat. no. 6085-1; Addgene, Cambridge, MA, USA) that included an insertion of BMP2 cDNA, and extracted plasmid-DNA was subjected to restriction enzyme analysis. The successful insertion of BMP2 cDNA fragments was confirmed through DNA sequencing, performed by the laboratory in Zhejiang University (Hangzhou, China). Purified pBMP2 was dissolved into $\mathrm{Na}_{2} \mathrm{SO}_{4}$ solution. The concentrations of $\mathrm{pBMP} 2$ used were 50,100 or $200 \mu \mathrm{g} / \mathrm{ml}$. Subsequently, chitosan was mixed with the different concentrations of pBMP2 to form CNPBs (CPB50, CPB100 and CPB200, respectively). Chitosan was purchased from Sigma-Aldrich; Merck Millipore (50 g; cat. no. 448877) (15).

Transfection efficiency of CNPBs. Experimental groups were established as follows: i) Blank control (untreated BMSCs); ii) positive control (200 $\mu \mathrm{g} / \mathrm{ml}$ pBMP2); iii) CPB50 (chitosan $+50 \mu \mathrm{g} / \mathrm{ml} \mathrm{pBMP} 2$ ); iv) CPB100 (chitosan + $100 \mu \mathrm{g} / \mathrm{ml}$ pBMP2); and v) CPB200 (chitosan $+200 \mu \mathrm{g} / \mathrm{ml}$ pBMP2). BMSCs were seeded into 6 -well culture plates $\left(5.0 \times 10^{5}\right.$ cells/well $)$ for $24 \mathrm{~h}$. Following the removal of DMEM, BMSCs were rinsed using $1 \mathrm{ml}$ DMEM. Next, pBMP2 and the different CNPB concentrations were added separately into the experimental wells for a 6-h incubation with Lipofectamine 2000 (Invitrogen; Thermo Fisher Scientific, Inc.). Green fluorescent protein (Guduo Corporation, Shanghai, China) was used as reporter. Following the removal of the transfection solution, BMSCs were continuously cultured with DMEM containing $1 \mathrm{ml}$ 10\% FBS for 24 h. BMSCs transfected with CNPBs were photographed using an inverted fluorescence microscope (XD30-RFL; Sunny Instruments Co., Ltd., Ningbo, China). The number of, and total area occupied by, the cells in the micrographs were analyzed using ImageJ version 1.42 (National Institutes of Health, Bethesda, MD, USA).

Cellular staining. Alkaline phosphatase staining, Wright's staining, and von Kossa staining were used for identification of osteoblast-like cells differentiated from the transfected BMSCs. Experimental groups included: i) Blank control; ii) CPB50; iii) CPB100; and iv) CPB200. Initially, BMSCs were seeded into 6 -well culture plates $\left(1.0 \times 10^{5}\right.$ cells/well $)$ and maintained overnight. Next, DMEM was removed, cells were rinsed using $1 \mathrm{ml}$ DMEM, the various concentrations of CNPB were added for the aforementioned specific treatment groups, and the cells were cultured for $24 \mathrm{~h}$ at $37^{\circ} \mathrm{C}$.

For alkaline phosphatase staining, the transfected BMSCs were fixed for $10 \mathrm{~min}$ in $4 \%$ paraformaldehyde and then rinsed using distilled water for 5-10 min. Cells were immersed in alkaline phosphatase solution for $25 \mathrm{~min}$ at $37^{\circ} \mathrm{C}$. Finally, cells were rinsed using distilled water for 5-10 $\mathrm{min}$.

For Wright's staining, the transfected BMSCs were rinsed with PBS and fixed in methanol for 3-5 min. Cells were treated with Wright's staining solution for $2 \mathrm{~min}$. Subsequently, transfected BMSCs were treated with Wright's phosphate buffer solution for 4-10 min and rinsed using distilled water.

Von Kossa staining was performed after transfected BMSCs were fixed in $4 \%$ paraformaldehyde for $15 \mathrm{~min}$. The cells were then rinsed with distilled water. Then, cells were treated in $1 \%$ silver nitrate solution and incubated 
Table I. Primers of ALP, OPG and OC.

\begin{tabular}{|c|c|c|}
\hline Primers & Sequences $\left(5^{\prime}-3^{\prime}\right)$ & Length (bp) \\
\hline Actin & $\begin{array}{l}\text { F: CTAAGGCCAACCGTGAAA; } \\
\text { R: TGGAAGGTGGACAGTGAG }\end{array}$ & 724 \\
\hline ALP & $\begin{array}{l}\text { F: GGTGGACGCAAAAATTTCAT; } \\
\text { R: ATGCCTTGATCGGTTTGTTC }\end{array}$ & 379 \\
\hline OPG & $\begin{array}{l}\text { F: CGACTGGAGAGCGAAGAC; } \\
\text { R: CTAAGCAATGTTGGCGTA }\end{array}$ & 364 \\
\hline $\mathrm{OC}$ & $\begin{array}{l}\text { F: GAGGACCCTCTCTCTGCTCA; } \\
\text { R: AGCTGTGCCGTCCATACTTT }\end{array}$ & 405 \\
\hline OPN & $\begin{array}{l}\text { F: CATCAGAGCCACCACTTTCA } \\
\text { R: TCAGGGCCCAAAACACTATC }\end{array}$ & 273 \\
\hline
\end{tabular}

ALP, alkaline phosphatase; OPG, osteoprotegerin; OC, osteocalcin; OPN, osteopontin; F, forward, R, reverse.

Table II. Quantity and total area of fluorescence particles in every group following transfection of bone marrow stem cells with chitosan nanoparticles containing plasmid-bone morphogenetic protein 2 sequences.

\begin{tabular}{lcc}
$\begin{array}{l}\text { Treatment } \\
\text { Groups }\end{array}$ & Count & Total area $\left(\mu \mathrm{m}^{2}\right)$ \\
\hline Positive control & $133.3 \pm 45.0$ & $9,189.3 \pm 5,632.1$ \\
CPB50 & $401.3 \pm 132.8$ & $33,494.0 \pm 19,076.8$ \\
CPB100 & $1,997.3 \pm 490.7$ & $250,702.6 \pm 20,510.9$ \\
CPB200 & $1,162.0 \pm 105.1$ & $219,652.0 \pm 65,961.3$ \\
\hline
\end{tabular}

Statistical analysis showed that there was a significant difference in particle quantity among the groups $(\mathrm{P}=0.000)$. There was a significant difference in total areas among groups $(\mathrm{P}=0.000)$. CPB50/100/200, chitosan nanoparticles containing plasmid-bone morphogenetic protein 2 at concentrations of 50,100 and $200 \mu \mathrm{g} / \mathrm{ml}$.

under an ultraviolet lamp for $15 \mathrm{~min}$. Finally, the cells were stained with $5 \%$ natrium hyposulfurosum solution (Shengrui Transmission Corporation Ltd., Xian, China) for $2 \mathrm{~min}$.

Reverse transcription-polymerase chain reaction (RT-PCR). Experimental groups included: i) Blank control; ii) CPB50; iii) CPB100; and iv) CPB200. BMSCs were seeded into 6-well culture plates $\left(1.0 \times 10^{5}\right.$ cells/well) for $24 \mathrm{~h}$ culture, $\mathrm{pBMP} 2$ was added, and each of the CNPB treatment groups were set up in separate experimental wells for a $48 \mathrm{~h}$ transfection. RT-PCR was used to determine the mRNA expression levels of ALP, OPG and OC in osteoblast-like cells. mRNA was extracted using TRIzol reagent (Invitrogen; Thermo Fisher Scientific, Inc.). The primers used for RT-PCR of ALP, OPG and OC are presented in Table I. A PCR kit with DNA-free sensitive Taq DNA polymerase (Amresco, LLC, Solon, OH, USA) was used. The RT conditions were: $37^{\circ} \mathrm{C}$ for $1 \mathrm{~h}$ and $95^{\circ} \mathrm{C}$ for $5 \mathrm{~min}$ in order to deactivate $\mathrm{M}-\mathrm{MLV}$ reverse transcriptase. The thermocycling conditions were as follows: $95^{\circ} \mathrm{C}$ for $15 \mathrm{~min}, 30$ cycles at $95^{\circ} \mathrm{C}$ for $15 \mathrm{sec}, 52^{\circ} \mathrm{C} 30 \mathrm{sec}, 72^{\circ} \mathrm{C}$ for $30 \mathrm{sec}$ and $72^{\circ} \mathrm{C}$ for $2 \mathrm{~min}$.
Western blotting. Protein expression levels of OPN in cells was detected using western blot analysis. Cells were rinsed twice using PBS. Cell lysis buffer $(100 \mu \mathrm{l})$ was added into each culture well (cat. no. P0013; Beyotime Institute of Biotechnology, Beijing, China). Cells were centrifuged for $5 \mathrm{~min}$ at $300 \mathrm{x} \mathrm{g}$ at $37^{\circ} \mathrm{C}$. Polyvinylidene fluoride membranes (Merck Millipore) were rinsed using PBS with Tween-20 (PBST). The membranes were incubated with the rabbit anti-OPN primary antibody (cat. no. 000019-R; 1:500; CellChip Biotechnology Co., Ltd., Beijing, China) for $1 \mathrm{~h}$ at $37^{\circ} \mathrm{C}$. PBST was used to wash the membranes 4 times for $10 \mathrm{~min}$ each. The membranes were then incubated for $1 \mathrm{~h}$ with a secondary biotin-labeled rabbit anti-goat IgG antibody (cat. no. E030330; 1:5,000; EarthOx Life Sciences, Millbrae, CA, USA). PBST was used to wash the membranes 4 times for $10 \mathrm{~min}$ each. The protein was then visualized using a Developer and fixer kit (cat. no. P0019, Beyotime Institute of Biotechnology), and the development time was 1-2 $\min$.

Ectopic bone formation. Polyglycolic acid scaffold materials (Dexon, Shanghai,China) were sterilized using 75\% alcohol and then cut into $0.5 \times 0.5 \times 0.5 \mathrm{~cm}^{2}$ pieces. The PGA scaffolds were soaked in DMEM for $2 \mathrm{~h}$, then $2 \mathrm{ml} \mathrm{BMSCs}\left(5.0 \times 10^{7}\right.$ cells $\left./ \mathrm{ml}\right)$ were seeded into the scaffolds as the negative control group. The following treatment groups were seeded onto the scaffolds: i) $\mathrm{BMSCs}+\mathrm{PGA}+\mathrm{CPB} 50$; ii) $\mathrm{BMSCs}+\mathrm{PGA}+\mathrm{CPB} 100$; and iii) $\mathrm{BMSCs}+\mathrm{PGA}+\mathrm{CPB} 200$. The PGA scaffolds were incubated for 5 days to ensure that cells and carriers had adhered successfully. The scaffolds were then implanted into the dorsal muscles of rats in order to determine the ectopic bone formation. Three scaffolds were implanted per treatment group. After 2 months, the 4 rats were euthanized by cervical dislocation and the regions with the implanted scaffolds were dissected. The tissues were then subjected to hematoxylin and eosin staining.

Statistical analysis. Data are presented as the mean \pm standard error. One-way analysis of variance was performed using SPSS version 17.0 software (SPSS, Inc., Chicago, IL, USA). $\mathrm{P}<0.05$ was considered to indicate statistically significant difference.

\section{Results}

Transfection efficiency of CNPBs. Following $24 \mathrm{~h}$ transfection of BMSCs no green fluorescence was observed in the blank control BMSC (untreated) group. However, green fluorescence was observed in the pBMP2 (positive control) and CNPB at different concentrations groups. This indicated that chitosan nanoparticles delivered the BMP2 gene into BMSCs and successfully displayed green fluorescence. The fluorescence of the pBMP2 and CPB50 groups was weaker compared with the CPB100 and CPB200 groups and particle analysis revealed that there was a greater quantity of fluorescence particles and in greater total areas in the CPB100 and CPB200 groups (Table II, and Figs. 1 and 2). Statistical analysis revealed that there was a significant difference in particle quantity among the groups $(\mathrm{P}<0.0001)$. Pairwise comparisons determined that there was a significant difference in particle quantity between any two groups, with the exception of the CPB50 and $\mathrm{pBMP} 2$ groups $(\mathrm{P}=0.243)$. There was also a significant 
A
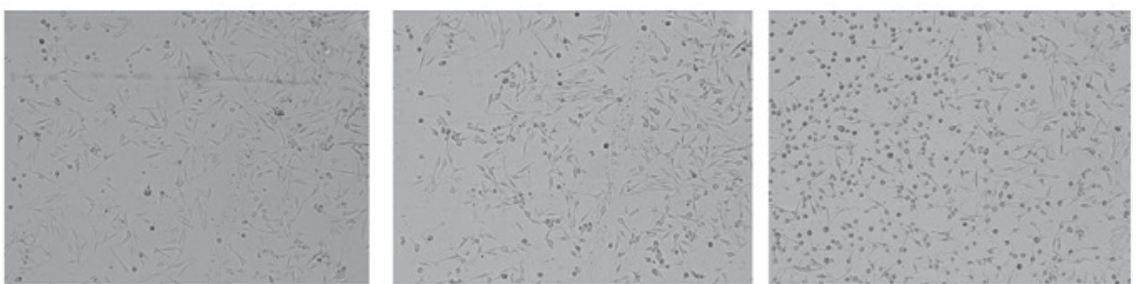

B
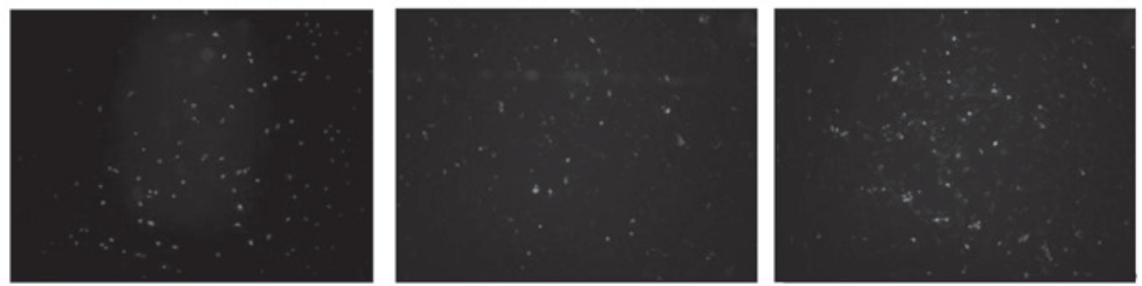

C
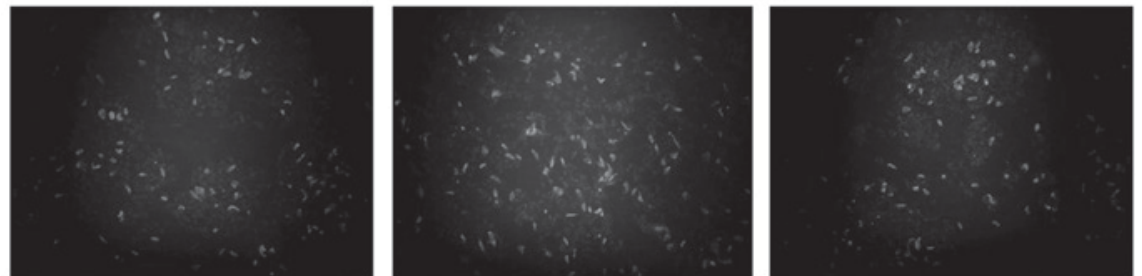

D
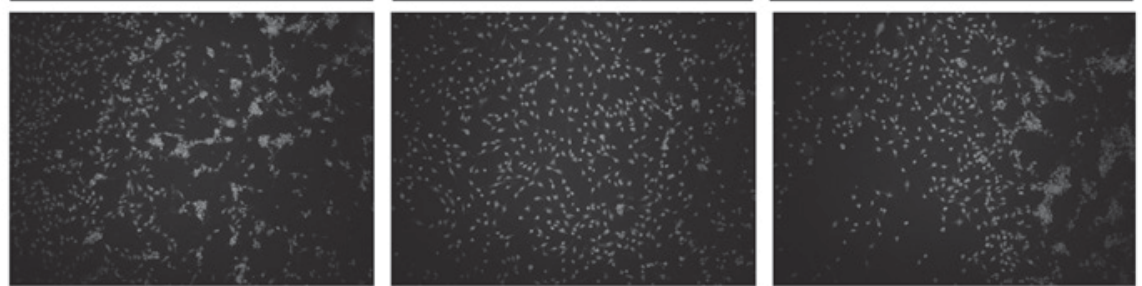

$\mathbf{E}$
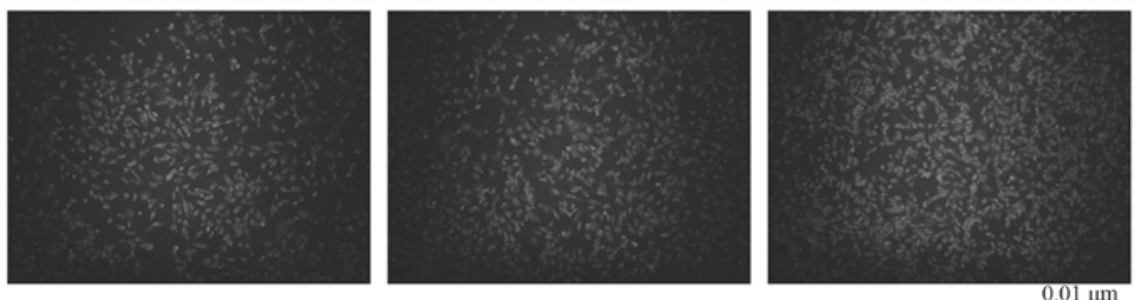

Figure 1. BMSCs with CNPBs transfection. (A) Blank control, (B) positive control, (C) CPB50, (D) CPB100 and (E) CPB200 groups. No fluorescence particles were observed in the untreated BMSC (blank control) group. A small number of fluorescence particles were observed in the positive control group (BMSCs exposed to pBMP2 only). There were many fluorescence particles observed in the CPB100 and CPB200 groups. BMSCs, bone marrow stem cells; pBMP2, plasmid bone morphogenetic protein 2; CPB50/100/200, chitosan nanoparticles containing plasmid-bone morphogenetic protein 2 at concentrations of 50,100 and $200 \mu \mathrm{g} / \mathrm{ml}$.
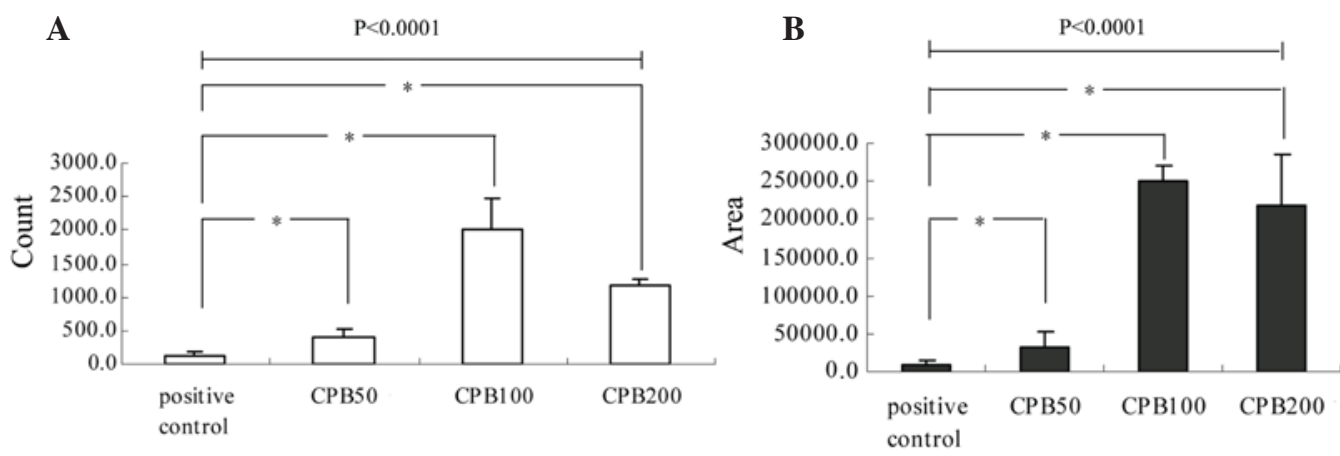

Figure 2. Histograms of the (A) quantity and (B) total area of fluorescent particles in bone marrow stem cells treatment groups. A larger quantity and larger total area of particles were observed in the CPB100 and CPB200 groups. CPB50/100/200, chitosan nanoparticles containing plasmid-bone morphogenetic protein 2 at concentrations of 50,100 and $200 \mu \mathrm{g} / \mathrm{ml} .{ }^{*} \mathrm{P}<0.00001$.

difference in total areas with fluorescence particles among the groups $(\mathrm{P}<0.0001)$. The difference in total areas between any two groups was significant, except between the CPB100 and CPB200 treatment groups ( $\mathrm{P}=0.321$; Table II, Figs. 1 and 2). 
Table III. Expression levels of ALP, OPG, OC, and OPN in osteoblast-like cells differentiated from BMSCs transfected with CNPBs.

\begin{tabular}{|c|c|c|c|c|}
\hline \multirow{2}{*}{$\begin{array}{l}\text { Groups } \\
\text { Objective genes }\end{array}$} & \multicolumn{2}{|c|}{ mRNA expression } & \multicolumn{2}{|c|}{ Protein expression } \\
\hline & ALP & OPG & $\mathrm{OC}$ & OPN \\
\hline Blank control & $148.8 \pm 4.5$ & $238.1 \pm 7.1$ & $116.0 \pm 4.3$ & $24.2 \pm 2.2$ \\
\hline СРB50 & $314.0 \pm 9.5$ & $372.7 \pm 9.8$ & $147.7 \pm 4.3$ & $53.3 \pm 2.4$ \\
\hline CPB100 & $467.0 \pm 6.3$ & $529.3 \pm 2.5$ & $262.2 \pm 5.4$ & $88.7 \pm 1.8$ \\
\hline СРВ200 & $485.2 \pm 15.5$ & $666.0 \pm 3.9$ & $292.8 \pm 6.6$ & $117.6 \pm 5.2$ \\
\hline Negative control & $151.3 \pm 6.2$ & $186.2 \pm 6.3$ & $88.7 \pm 2.1$ & $16.6 \pm 0.7$ \\
\hline
\end{tabular}

Statistical analysis determined that there was a significant difference between any two groups $(\mathrm{P}<0.0001)$, except between the blank control and negative control groups $(\mathrm{P}=0.751)$. ALP, alkaline phosphatase; OPG, osteoprotegerin; OC, osteocalcin; OPN, osteopontin; BMSCs, bone marrow stem cells; CNPBs, chitosan nanoparticles containing plasmid-bone morphogenetic protein 2 sequences; CPB50/100/200, chitosan nanoparticles containing plasmid-bone morphogenetic protein 2 at concentrations of 50, 100 and $200 \mu \mathrm{g} / \mathrm{ml}$.
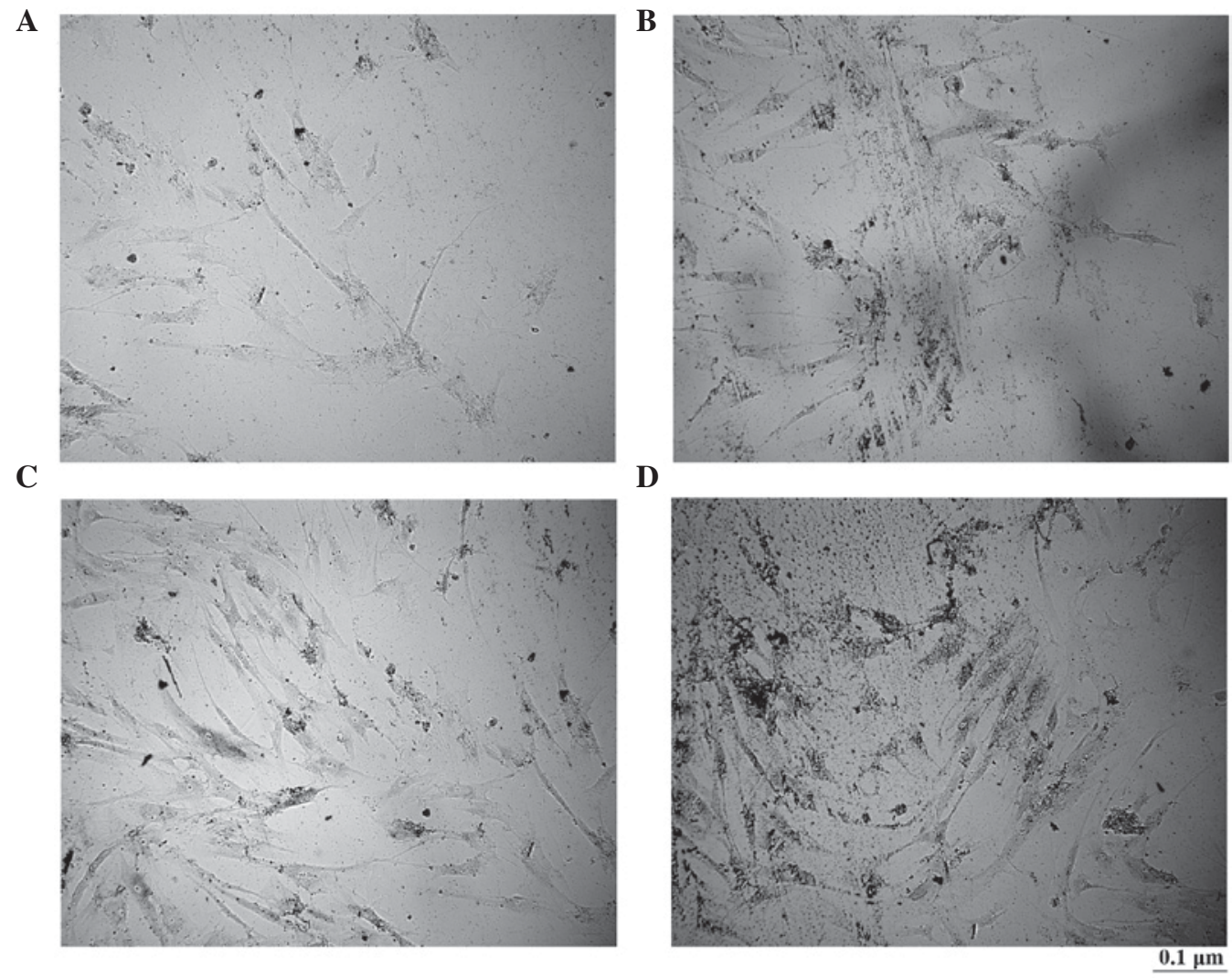

Figure 3. Alkaline phosphatase staining of osteoblast-like cells. (A) Control; (B) CPB50; (C) CPB100; and (D) CPB200. No brownish-black particles were observed in the control group. The number of brownish-black particles increased in the CBP200 group. CPB50/100/200, chitosan nanoparticles containing plasmid-bone morphogenetic protein 2 at concentrations of 50,100 and $200 \mu \mathrm{g} / \mathrm{ml}$.

Alkaline phosphatase staining of osteoblast-like cells differentiated from transfected BMSCs with CNPBs. There were no obvious brownish-black particles observed in the control group; however, there were numerous brownish-black particles in the CPB50, CPB100 and CPB200 groups. In addition, more particles were observed in the CPB200 group compared with the CPB50 and CPB100 groups (Fig. 3).

Wright's staining of osteoblast-like cells differentiated from BMSCs transfected with CNPBs. The staining revealed that
BMSCs of a smaller size were fibriform in the control group (Fig.4A). However, osteoblast-like cells that differentiated from BMSCs were observed to be larger in size, with inflated cell bodies and nucleoli stained dark blue in the CBP50, CBP100 and CBP200 treatment groups. In addition, osteoblast-like cells also had characteristic stick-like prominences (Fig. 4).

Von Kossa staining of osteoblast-like cells differentiated from BMSCs transfected with CNPBS. No staining was observed in the control group (Fig. 5A). Black particles, indicating 
A

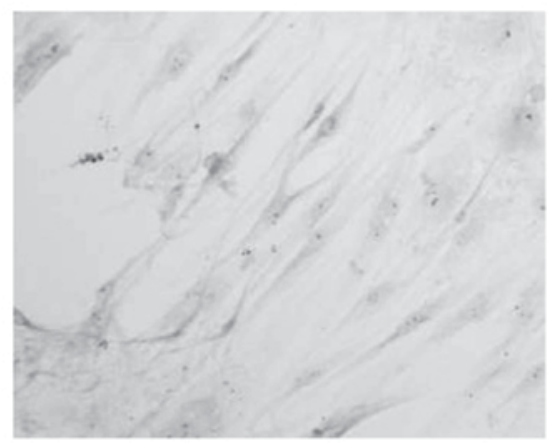

C

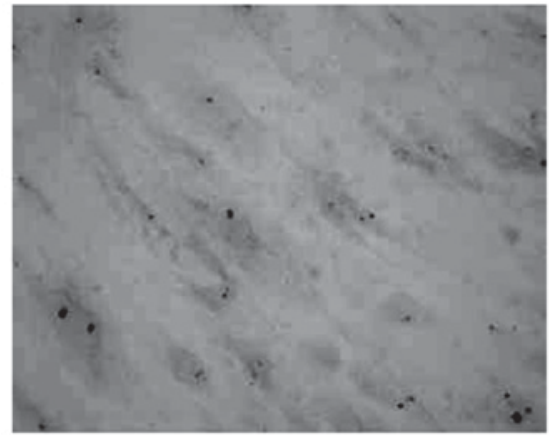

B

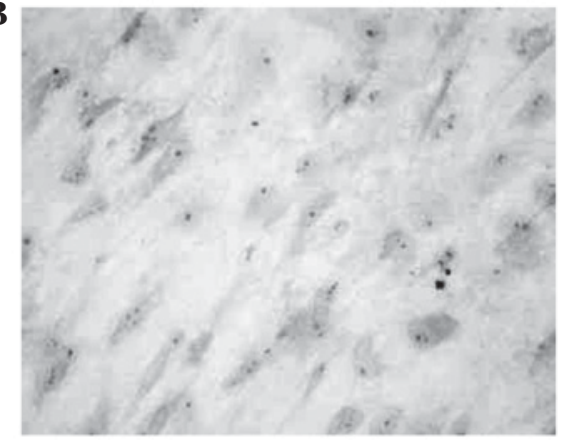

D

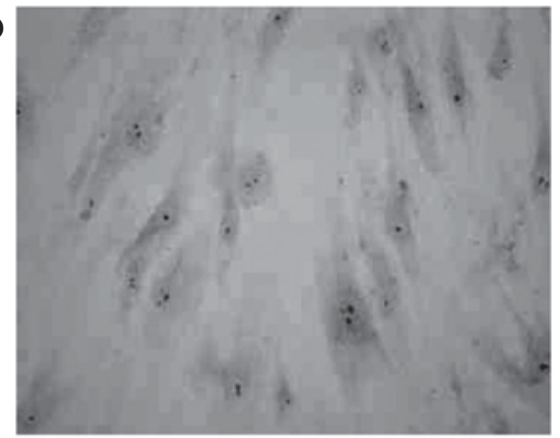

$\underline{0.1 \mu \mathrm{m}}$

Figure 4. Wright's staining of BMSCs transfected with CNPBs of (A) control, (B) CPB50, (C) CPB100 and (D) CPB200 groups. Differences among the treatment groups were identified. Osteoblast-like cells with characteristic stick-like prominences differentiated from BMSCs were larger, with inflated cell bodies and their nucleoli had dark blue staining in the CBP200 group. BMSCs, bone marrow stem cells; pBMP2, plasmid bone morphogenetic protein 2; CNPBs, chitosan nanoparticles containing plasmid-bone morphogenetic protein 2 sequences; CPB50/100/200, chitosan nanoparticles containing plasmid-bone morphogenetic protein 2 at concentrations of 50,100 and $200 \mu \mathrm{g} / \mathrm{ml}$.

A

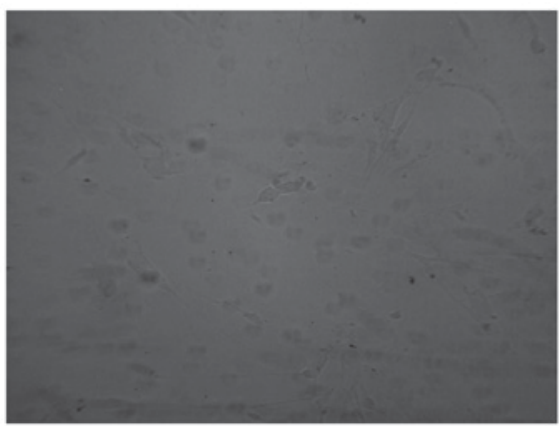

C

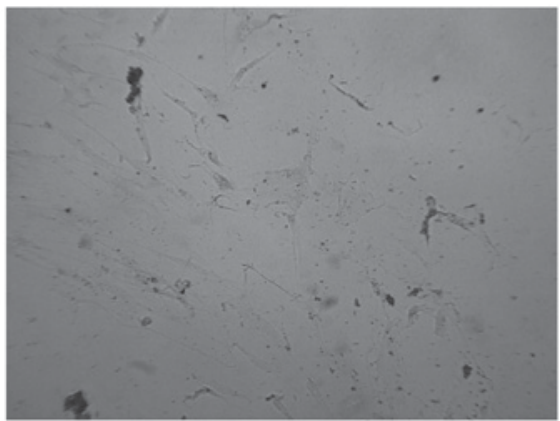

B

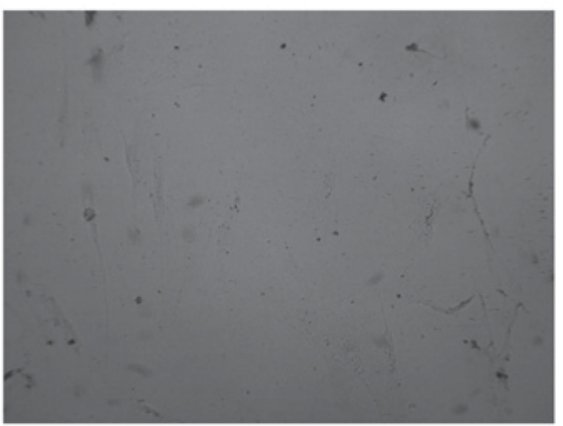

D

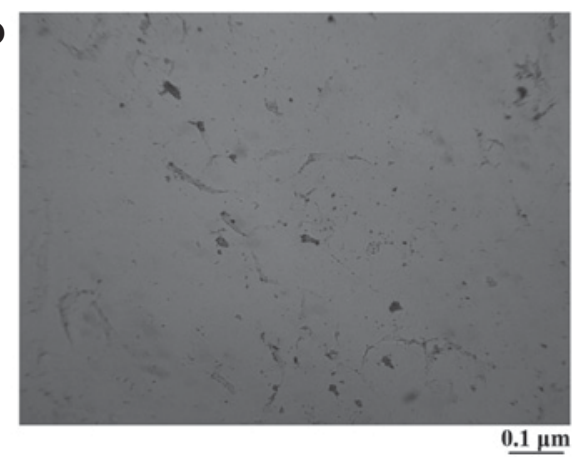

Figure 5. Von Kossa staining of BMSCs transfected with CNPBs. (A) Control; (B) CPB50; (C) CPB100; and (D) CPB200. Black nodes observed in the CNPB groups; however, they were not observed in the control group. BMSCs, bone marrow stem cells; pBMP2, plasmid bone morphogenetic protein 2; CNPBs, chitosan nanoparticles containing plasmid-bone morphogenetic protein 2 sequences; CPB50/100/200, chitosan nanoparticles containing plasmid-bone morphogenetic protein 2 at concentrations of 50,100 and $200 \mu \mathrm{g} / \mathrm{ml}$.

a positive reaction of calcium phosphate in the mineralized extracellular matrix of osteoblasts, were observed in the CPB50, CPB100 and CPB200 treatment groups (Fig. 5B-D).
Expression levels of $A L P, O P G, O C$ and $O P N$ in osteoblast-like cells differentiated from BMSCs transfected with CNPBs. The RT-PCR determined that the mRNA expression levels of 


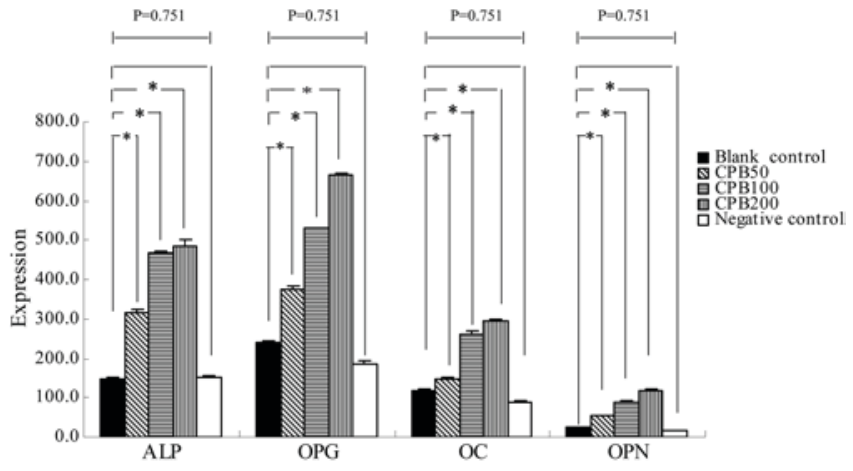

Figure 6. Expression levels of ALP, OPG, OC and OPN. The highest mRNA expression levels were found in the CPB200 group. Significantly lower expressions of genes were observed in the control groups. ALP, alkaline phosphatase; OPG, osteoprotegerin; OC, osteocalcin; OPN, osteopontin; CNPBs, chitosan nanoparticles containing plasmid-bone morphogenetic protein 2 sequences; CPB50/100/200, chitosan nanoparticles containing plasmid-bone morphogenetic protein 2 at concentrations of 50, 100 and $200 \mu \mathrm{g} / \mathrm{ml} .{ }^{*} \mathrm{P}<0.0001$.

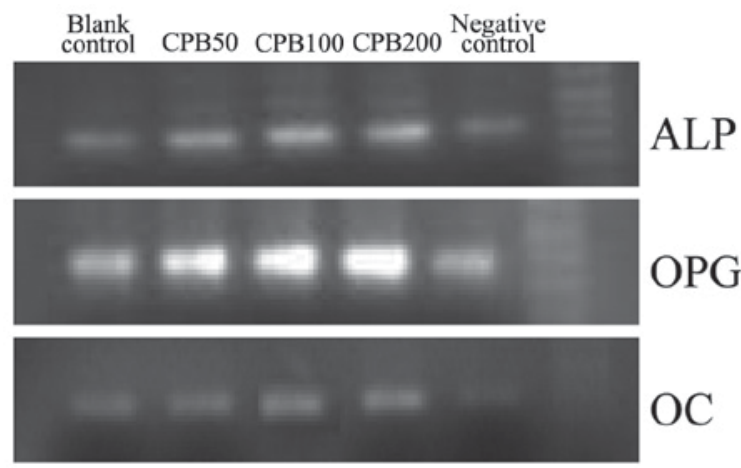

Figure 7. Gel electrophoresis of ALP, OPG, and OC. mRNA expression levels of ALP, OPG, and OC were evident in the CPB200 group. ALP, alkaline phosphatase; OPG, osteoprotegerin; OC, osteocalcin; CPB50/100/200, chitosan nanoparticles containing plasmid-bone morphogenetic protein 2 at concentrations of 50,100 and $200 \mu \mathrm{g} / \mathrm{ml}$.

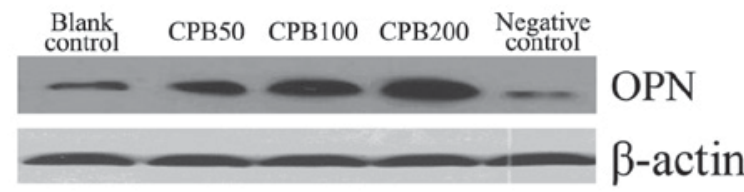

Figure 8 . Western blotting was performed in order to determine the protein expression levels of OPN in the various treatment groups. The CPB200 group had the highest expression levels. OPN, osteopntin; CPB50/100/200, chitosan nanoparticles containing plasmid-bone morphogenetic protein 2 at concentrations of 50,100 and $200 \mu \mathrm{g} / \mathrm{ml}$.

ALP, OPG, OC and OPN were increased in the CNPB treatment groups compared with the blank and negative control groups (Fig. 6). The highest mRNA expression levels of ALP, OPG, OC and OPN were identified in the CPB200 treatment group (Table III; Figs. 6-8). Statistical analysis revealed that there was a significant difference between any two groups $(\mathrm{P}<0.0001)$, except between the blank and negative control groups $(\mathrm{P}=0.751)$.

Ectopic bone formation. Two months after the PGA scaffolds that were integrated with BMSCs transfected with CNPBs
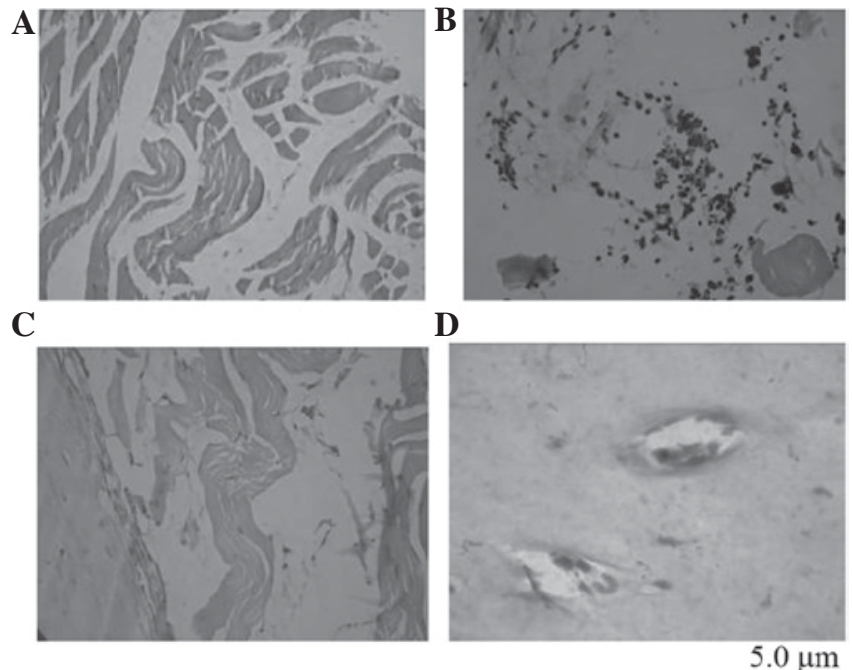

Figure 9. Histological staining of ectopic bone formation test. (A) Red staining of muscle fibers was evident in the control group. (B) CPB200 group had aggregating lymphocytes in the implanted regions. (C) A classic bone tissue image in the CPB200 group. (D) Bone lacunae were evident in the CPB200 group. CPB200, chitosan nanoparticles containing plasmid-bone morphogenetic protein 2 at concentration of $200 \mu \mathrm{g} / \mathrm{ml}$.

were implanted into the muscles of rats, by touch, the sensation of a 'string-like' object in the subdermal implanted regions of the control and CPB50 groups was identified. However, a node-like object was identified in the subdermal implanted regions of the CPB100 and CPB200 groups. After the implanted regions were excised, numerous muscle fibers were observed in the control and CPB50 groups. In the CPB100 and CPB200 groups, a dark-red node with white spots was identified, which was surrounded by fibrous tissues. Histological staining revealed that there was novel bone formation had occurred in the CPB100 and CPB200 treatment groups (Fig. 9). This bone formation was more evident in the CBP200 group. In the positions of white spots were determined to be cartilage islands (Fig. 9). The PGA scaffolds were absorbed in all treatment groups.

\section{Discussion}

Chitosan is considered to be an effective non-viral carrier and is extensively used for tissue engineering $(13,16)$. In our previous study (15), chitosan nanoparticles had excellent biocompatibility. On the basis of these results, the present study used chitosan nanoparticles as carriers of genetic material. CNPBs had excellent transfection efficiency to BMSCs and induced the differentiation and proliferation of osteoblast-like cells. In addition, CNPBs induced ectopic formation of new bone in rats. Therefore, the present study determined that CNPBs are promising carriers of genetic material.

BMSCs have been used extensively in bone tissue engineering. As BMSCs are capable of multi-directional differentiation, bone growth factors and osteogenesis are important factors to consider for successful bone tissue engineering. Bone growth factors primarily include the BMP family, transforming growth factor- $\beta$, dexamethasone, the active form of vitamin D [1,25-(OH) 2D3], vitamin C and sodium glycerophosphate. The exogenous BMP family is a group of acid 
polypeptides with low molecular weights. BMP2 may promote cell proliferation and induce seed cells to differentiate into osteoblast-like cells, which may result in the formation of new bone. Hou et al (16) determined that BMP2 had potent osteoinductive properties in bone regeneration (16). The composite scaffold that Hou et al (16) constructed of recombinant human BMP2 (rhBMP2)-loaded collagen/chitosan microspheres bridged bone defects and recanalized the bone-marrow cavity. The results of a previous study indicated that BMP2 alone had a positive effect on bone regeneration (17). Yilgor et al (18) revealed that treatment with BMP2 alone resulted in a higher ALP activity compared with treatment with BMP7 (18).

In the present study, BMSCs were transfected with CNPBs. BMP2 was released continuously during osteogenesis to promote formation of new bone. Therefore, the present study determined that BMSCs transfected with CNPBs at a higher efficiency. The phenotype of osteoblast-like cells was confirmed using alkaline phosphatase, Wright's, von Kossa staining. In addition, the mRNA and protein expression levels of ALP, OPG, OC and OPN in osteoblast-like cells differentiated from the transfected BMSCs were recorded at higher levels compared with the control group, which had untreated cells. In order to determine the extent of ectopic bone formation, CNPBs were attached to PGA scaffolds to induce new bone formation following implantation into the dorsal muscles of rats.

Chitosan gels loaded with BMP2 enhanced ALP activity in BMSCs by 3.6-fold, and increased the calcium mineral deposition of mesenchymal cells by 2.8 -fold (19). In addition, chitosan gels loaded with BMP2 induced synthesis of OC in BMSCs (19). The present study was consistent with the findings of previous studies (20-22). Zhao et al (20) determined that a calcium phosphate-chitosan fibrous scaffold delivery system with BMP2 promoted osteo-differentiation and resulted in increased gene expression levels of ALP and OC (20). Shi et al (21) demonstrated that carboxymethyl chitosan-BMP2 modified substrates significantly promoted ALP activity and calcium mineral deposition of osteoblasts and human bone marrow-derived mesenchymal stem cells (21). Additionally, bone formation was observed in the quadriceps muscles of rats following the implantation of rhBMP2-loaded chitosan carriers (22).

The BMP2-induced differentiation of BMSCs into osteoblast-like cells ensures that BMP2 is able to recruit BMSCs and promote their proliferation. During bone formation, BMP2 promotes cellular differentiation and proliferation through autocrine and paracrine secretion. Following BMP2 binding to the BMP2-specific receptor on the cell surface, Smad protein becomes activated through signal transmission. Subsequently, Smad protein is transported into the cell nuclei. Next, the nuclear factor, runt-related transcription factor 2 (Runx2; also known as core-binding factor subunit- $\alpha 1$ ), is activated through the mitogen-activated protein kinase pathway. Following the combination of Runx 2 with Smad, specific phenotypes in osteoblast-like cells are activated sequentially (16-22). Finally, expression levels of ALP, OPG, OC and OPN were upregulated, and BMSCs were differentiated into osteoblast-like cells.

Scaffold materials may primarily include natural and synthesis polymer and bioceramics (23). Natural polymers such as collagen, chitosan-alginate gel and hyaluronic acid may be used. Synthesized polymers that are biodegradable include polyactide, polyviol, polyacrylic acid and polyethylene glycol. The primary bioceramics used are calcium phosphate ceramics, hydroxyapatite and calcium carbonate $(24,25)$. Chen et al (26) used bilayered integrated scaffolds in their study. Their findings revealed that mesenchymal stem cells seeded in each layer of the bilayered gene-activated osteochondral scaffold had a higher expression of BMP2 protein (26). Park et al (27) determined that chitosan-alginate gel/mesenchymal stem cell/BMP2 composites were able to stimulate novel bone formation. The primary aim of tissue engineering is to construct a three-dimensional complex composed of seed cells and biomaterials. Therefore, PGA scaffolds with the same excellent biocompatibility and biodegradability have been used extensively in bone tissue engineering. The present study involved the transfection of BMSCs with CNPBs, and they were subsequently incubated with PGA scaffolds. Cells adhered to, and proliferated on, the PGA scaffolds. The histological staining revealed that the PGA scaffolds had successfully degraded, and novel bone formation was observed. The present study determined that PGA scaffolds with three-dimensional structures provided a larger surface area, and simulated the formation of natural bone structures. This allowed for the slow release of BMP2 in the CNPBs, providing an excellent 'shelter' for osteoblast-like cells differentiated from BMSCs. This promoted the osteogenic functions of osteoblast-like cells.

In conclusion, in the present study CNPBs were successfully transfected into BMSCs with a high efficiency, and BMSCs were promoted to differentiate into osteoblast-like cells in vitro. Additionally, CNPBs upregulated the expression levels of ALP, OPG, OC and OPN in osteoblast-like cells and induced the formation of new ectopic bone in vivo.

\section{Acknowledgements}

The present study was supported by the Department of Education Foundation of Zhejiang Province of China (grant nos. 20080180, Y201018976 and N20110143), Zhejiang Provincial Natural Science Foundation of China (grant nos. Y2080340 and LY12H14004) and Zhejiang Provincial and Ministry Joint Project (grant no. WKJ2011-2-009).

\section{References}

1. Amini AR, Laurencin CT and Nukavarapu SP: Differential analysis of peripheral blood- and bone marrow-derived endothelial progenitor cells for enhanced vascularization in bone tissue engineering. J Orthop Res 30: 1507-1515, 2012.

2. Takekawa M, Matsuda M and Ohotubo S: Effect of irradiation on autogenous bone transplantation in rat parietal bone. Histol Histopathol 15: 7-19, 2000.

3. Erlwein $\mathrm{O}$ and McClure M: Gene delivery the key to gene therapy: The case for foamy viruses. Ther Deliv 2: 681-684, 2011.

4. Moawad HM and Jain H: Fabrication of nano-macroporous glass-ceramic bioscaffold with a water soluble pore former. J Mater Sci Mater Med 23: 307-314, 2012.

5. Fazil M, Md S, Haque S, Kumar M, Baboota S, Sahni JK and Ali J: Development and evaluation of rivastigmine loaded chitosan nanoparticles for brain targeting. Eur J Pharm Sci 47: 6-15, 2012.

6. Yadav A, Lomash V, Samim M and Flora SJ: Curcumin encapsulated in chitosan nanoparticles: A novel strategy for the treatment of arsenic toxicity. Chem Biol Interact 199: 49-61, 2012. 
7. Al Faqeh H, Nor Hamdan BM, Chen HC, Aminuddin BS and Ruszymah BH: The potential of intra-articular injection of chondrogenic-induced bone marrow stem cells to retard the progression of osteoarthritis in a sheep model. Exp Gerontol 47: 458-464, 2012.

8. Zou D, Han W, You S, Ye D, Wang L, Wang S, Zhao J, Zhang W Jiang X, Zhang X and Huang Y: In vitro study of enhanced osteogenesis induced by HIF-1 $\alpha$-transduced bone marrow stem cells. Cell Prolif 44: 234-243, 2011

9. Bhakta G, Rai B, Lim ZX, Hui JH, Stein GS, van Wijnen AJ, Nurcombe V, Prestwich GD and Cool SM: Hyaluronic acid-based hydrogels functionalized with heparin that support controlled release of bioactive BMP-2. Biomaterials 33: 6113-6122, 2012.

10. Hunziker EB, Enggist L, Küffer A, Buser D and Liu Y: Osseointegration: The slow delivery of BMP-2 enhances osteoinductivity. Bone 51: 98-106, 2012.

11. Santos JL, Pandita D, Rodrigues J, Pêgo AP, Granja PL and Tomás H: Non-viral gene delivery to mesenchymal stem cells: Methods, strategies and application in bone tissue engineering and regeneration. Curr Gene Ther 11: 46-57, 2011.

12. Fernández MS, Arias JI, Martínez MJ, Saenz L, Neira-Carrillo A, Yazdani-Pedram M and Arias JL: Evaluation of a multilayered chitosan-hydroxy-apatite porous composite enriched with fibronectin or an in vitro-generated bone-like extracellular matrix on proliferation and diferentiation of osteoblasts. J Tissue Eng Regen Med 6: 497-504, 2012.

13. Peschel D, Zhang K, Fischer S and Groth T: Modulation of osteogenic activity of BMP-2 by cellulose and chitosan derivatives. Acta Biomater 8: 183-193, 2012.

14. Lee D and Mohapatra SS: Chitosan nanoparticle-mediated gene transfer. Methods Mol Biol 433: 127-140, 2008

15. Liu MT, Zhang QH, Zhai JJ and Liang X: Construction and analysis of one kind of chitosan-coated BMP-2 nanoparticles as genetic carrier. Sichuan Da Xue Xue Bao Yi Xue Ban 42: 485-489, 2011.

16. Hou J, Wang J, Cao L, Qian X, Xing W, Lu J and Liu C: Segmental bone regeneration using rhBMP-2-loaded collagen/chitosan microspheres composite scaffold in a rabbit model. Biomed Mater 7: 035002, 2012.

17. Canter HI, Vargel I, Korkusuz P, Oner F, Gungorduk DB, Cil B, Karabulut E, Sargon MF and Erk Y: Effect of use of slow release of bone morphogenetic protein-2 and transforming growth factor-Beta-2 in a chitosan gel matrix on cranial bone graft survival in experimental cranial critical size defect model. Ann Plast Surg 64: 342-350, 2010
18. Yilgor P, Tuzlakoglu K, Reis RL, Hasirci N and Hasirci V: Incorporation of a sequential BMP-2/BMP-7 delivery system into chitosan-based scaffolds for bone tissue engineering. Biomaterials 30: 3551-3559, 2009.

19. Kim S, Tsao H, Kang Y, Young DA, Sen M, Wenke JC and Yang Y: In vitro evaluation of an injectable chitosan gel for sustained local delivery of BMP-2 for osteoblastic differentiation. J Biomed Mater Res B Appl Biomater 99: 380-390, 2011.

20. Zhao L, Tang M, Weir MD, Detamore MS and Xu HH: Osteogenic media and rhBMP-2-induced differentiation of umbilical cord mesenchymal stem cells encapsulated in alginate microbeads and integrated in an injectable calcium phosphate-chitosan fibrous scaffold. Tissue Eng Part A 17: 969-979, 2011

21. Shi Z, Neoh KG, Kang ET, Poh CK and Wang W: Surface functionalization of titanium with carboxymethyl chitosan and immobilized bone morphogenetic protein-2 for enhanced osseointegration. Biomacromolecules 10: 1603-1611, 2009.

22. Luca L, Rougemont AL, Walpoth BH, Gurny R and Jordan O The effects of carrier nature and $\mathrm{pH}$ on rhBMP-2-induced ectopic bone formation. J Control Release 147: 38-44, 2010.

23. Mishra S, Rajyalakshmi A and Balasubramanian K: Compositional dependence of hematopoietic stem cells expansion on bioceramic composite scaffolds for bone tissue engineering. J Biomed Mater Res A 100: 2483-2491, 2012.

24. Do TN, Lee WH, Loo CY, Zavgorodniy AV and Rohanizadeh R: Hydroxyapatite nanoparticles as vectors for gene delivery. Ther Deliv 3: 623-632, 2012

25. Lee GS, Park JH, Shin US and Kim HW: Direct deposited porous scaffolds of calcium phosphate cement with alginate for drug delivery and bone tissue engineering. Acta Biomater 7: 3178-3186, 2011

26. Chen J, Chen H, Li P, Diao H, Zhu S, Dong L, Wang R, Guo T, Zhao J and Zhang J: Simultaneous regeneration of articular cartilage and subchondral bone in vivo using MSCs induced by a spatially controlled gene delivery system in bilayered integrated scaffolds. Biomaterials 32: 4793-4805, 2011.

27. Park DJ, Choi BH, Zhu SJ, Huh JY, Kim BY and Lee SH Injectable bone using chitosan-alginate gel/mesenchymal stem cells/BMP-2 composites. J Craniomaxillofac Surg 33: 50-54, 2005. 